\title{
EGU21-3772
}

https://doi.org/10.5194/egusphere-egu21-3772

EGU General Assembly 2021

(c) Author(s) 2021. This work is distributed under

the Creative Commons Attribution 4.0 License.

\section{Local natural background levels assessment through a groundwater redox zonation, the case of Lombardy Region.}

\author{
Marco Rotiroti ${ }^{1}$, Mariachiara Caschetto ${ }^{1}$, Chiara Zanotti ${ }^{1}$, Marco Parini ${ }^{2}$, Giuseppa Cipriano ${ }^{3}$, \\ Tullia Bonomi ${ }^{1}$, and Letizia Fumagalli ${ }^{1}$ \\ ${ }^{1}$ Department of Earth and Environmental Sciences, University of Milano-Bicocca, Piazza della Scienza 1, 20126 Milano, Italy. \\ ${ }^{2}$ Regione Lombardia, Direzione Generale Territorio e Protezione Civile, Struttura Risorse Idriche, Piazza Città di Lombardia \\ 1, 20124 Milano, Italy. \\ ${ }^{3}$ Agenzia Regionale per la Protezione dell'Ambiente della Lombardia, Settore Monitoraggi Ambientali, Via Rosellini 17, 20124 \\ Milano, Italy.
}

Discretizing anthropogenic and natural contaminations represents a crucial step in groundwater management and regulation. Natural background levels (NBLS) have a huge impact on groundwater protections and remediation strategies, but it is still an issue on the ground in terms of reliability and accuracy, thus its derivation needs further scientific efforts.

The derivation of local NBLS (LNBLS) is intended to overcome the limitation of considering a groundwater body (GWB) homogeneous, hence accounting hydrogeochemical heterogeneities within the aquifer system.

This work presents a statistical approach assessing LNBLs for sensitive redox species (As, Fe, Mn, $\mathrm{NH}_{4}$ ) in 30 GWBs within the Lombardy Region. Under the monitoring network of the Regional Agency for Environmental Protection of Lombardy (ARPA), more than 500 wells were investigated, thus each GWBs were identified within 4 aquifer types: shallow, intermediate, deep Po Plain aquifers and Alpine valley aquifers. The initial dataset underwent preselection and multivariate analyses, appointing at each well a geogenic redox zonation. It leaded to discretize geochemicallyhomogeneous subgroups and characterize them as function of site-specific natural facies: oxidised (293 wells), reduced (199 wells) and saline (11 wells). Interquartile range criteria, validations' tests (Mann-Kendall and Shapiro-Wilk), probability density histograms and probability plots inferred temporally and spatially the datasets, one for each target species, discretized for aquifer and natural facies appartenances. This resulted in the identification of the statistical distributions from redox-homogeneous sets of data from which the LNBLs were derived.

Considering the Po Plain aquifer (shallow, intermediate and deep), NBLs derivation for As revealed three subgroups within the oxidised facies, for which the NBLs values are of 2, 3 and $7 \mu \mathrm{g} / \mathrm{L}$, four subgroups ascribe to the reduced facies with NBLs of 13, 49, 71 and $291 \mu \mathrm{g} / \mathrm{L}$, and two subgroups for the saline facies with NBLs of 3 and $12 \mu \mathrm{g} / \mathrm{L}$. According Fe, two are the subgroups within the oxidised facies, with NBLs of 40 and $94 \mu \mathrm{g} / \mathrm{L}$, four subgroups fall in the reduced facies with NBLs of $653,1430,3200$ and $6000 \mu \mathrm{g} / \mathrm{L}$; within the saline facies, two subgroups are identified with NBLs of 
1647 and $6000 \mu g / L$. Two subgroups characterize the oxidised facies for NBLs of Mn with values of 8 and $27 \mu \mathrm{g} / \mathrm{L}$, and NBLs of 34, 216, 485, 912 and $1514 \mu \mathrm{g} / \mathrm{L}$ refer to five subgroups in reduced facies, while within the saline facies fall two subgroups with NBLs of 381 and $921 \mu \mathrm{g} / \mathrm{L}$. With regards to $\mathrm{NH}_{4}, \mathrm{NBLS}$ reach values of 49,110 and $190 \mu \mathrm{g} / \mathrm{L}$ for the three subgroups within the oxidised facies, whereas values of $834,2600,3090,4480 \mu \mathrm{g} / \mathrm{L}$ are derived for the four subgroups in the reduced facies; the two subgroups ascribed to the saline facies reveal NBLs of 1860 and 6620 $\mu g / L$.

Data demonstrate how an in depth understanding of aquifers' redox-zonations turned out to be functional for assessing LNBLs. Regional Legislation (D.G.R. 23novembre2020 n.3903) has been amended on the basis of the outcomes of this work, revealing site redox-specific LNBLs of practical significance.

Funding: this work was granted and carried out in collaboration with Lombardy Region. 